\title{
Mercury Dynamics in a San Francisco Estuary Tidal Wetland: Assessing Dynamics Using In Situ Measurements
}

\author{
Brian A. Bergamaschi • Jacob A. Fleck • \\ Bryan D. Downing • Emmanuel Boss • \\ Brian A. Pellerin • Neil K. Ganju • \\ David H. Schoellhamer • Amy A. Byington • \\ Wesley A. Heim • Mark Stephenson • Roger Fujii
}

Received: 6 August 2011 /Revised: 17 March 2012 / Accepted: 20 March 2012 / Published online: 3 April 2012

(C) The Author(s) 2012. This article is published with open access at Springerlink.com

\begin{abstract}
We used high-resolution in situ measurements of turbidity and fluorescent dissolved organic matter (FDOM) to quantitatively estimate the tidally driven exchange of mercury $(\mathrm{Hg})$ between the waters of the San Francisco estuary and Browns Island, a tidal wetland. Turbidity and FDOM - representative of particle-associated and filterpassing $\mathrm{Hg}$, respectively - together predicted $94 \%$ of the observed variability in measured total mercury concentration in unfiltered water samples (UTHg) collected during a single tidal cycle in spring, fall, and winter, 2005-2006. Continuous in situ turbidity and FDOM data spanning at least a full spring-neap period were used to generate UTHg
\end{abstract}

B. A. Bergamaschi $(\bowtie) \cdot$ J. A. Fleck $\cdot$ B. D. Downing $\cdot$

B. A. Pellerin - D. H. Schoellhamer $\cdot$ R. Fujii

United States Geological Survey California Water Science Center, 6000 J Street,

Sacramento, CA 95819-6129, USA

e-mail: bbergama@usgs.gov

E. Boss

University of Maine School of Marine Sciences,

Orono, ME 04469, USA

\section{N. K. Ganju}

United States Geological Survey Woods Hole Science Center, 384 Woods Hole Road,

Woods Hole, MA 02543-1598, USA

\section{A. A. Byington · W. A. Heim}

Moss Landing Marine Laboratories,

8272 Moss Landing Road,

Moss Landing, CA 95039, USA

\section{Stephenson}

California Department of Fish and Game Marine Pollution Studies Laboratory,

7544 Sandholdt Rd,

Moss Landing, CA 95039, USA concentration time series using this relationship, and then combined with water discharge measurements to calculate $\mathrm{Hg}$ fluxes in each season. Wetlands are generally considered to be sinks for sediment and associated mercury. However, during the three periods of monitoring, Browns Island wetland did not appreciably accumulate $\mathrm{Hg}$. Instead, gradual tidally driven export of UTHg from the wetland offset the large episodic on-island fluxes associated with high wind events. Exports were highest during large spring tides, when ebbing waters relatively enriched in FDOM, dissolved organic carbon (DOC), and filter-passing mercury drained from the marsh into the open waters of the estuary. On-island flux of UTHg, which was largely particleassociated, was highest during strong winds coincident with flood tides. Our results demonstrate that processes driving UTHg fluxes in tidal wetlands encompass both the dissolved and particulate phases and multiple timescales, necessitating longer term monitoring to adequately quantify fluxes.

Keywords Mercury · Tidal wetlands · San Francisco Bay . Sacramento River - Delta · Mercury flux · Sediment flux . Rivers $\cdot$ Wetlands $\cdot$ Estuaries $\cdot$ Wetland restoration

\section{Introduction}

Mercury ( $\mathrm{Hg}$ ) accumulation in estuarine food webs is of concern because high tissue concentrations in fishes and birds (Mason et al. 2006; Eagles-Smith and Ackerman 2009; Smith et al. 2009) have been associated with neurological and behavioral abnormalities, low reproductive success, and direct toxicity (Adams and Frederick 2008; Mitro et al. 2008; Crump and Trudeau 2009). Estuaries are particularly vulnerable to $\mathrm{Hg}$ contamination because they are 
often the receiving water bodies for sedimentary fluxes of mercury from upland areas.

Many studies of $\mathrm{Hg}$ cycling in the sediments of estuarine open waters have been reported (reviewed in Merritt and Amirbahman 2009), but little is known about cycling in and exports from estuarine tidal wetlands (Mitchell and Gilmour 2008; Bergamaschi et al. 2011; Bergamaschi et al. 2012). Such wetlands are potentially important in regional mercury dynamics because they typically trap river-borne sediments (Ganju et al. 2005); they host elevated levels of dissolved organic carbon (DOC), which can solubilize Hg (Amirbahman et al. 2002; Bergamaschi et al. 2011); and they are important sites of methylmercury production (Hall et al. 2008). Further, tidal exchange between estuarine wetlands and the surrounding waters can drive material exchanges of fine sedimentary material or dissolved organic matter (Eckard et al. 2007; Hall et al. 2008; Kraus et al. 2008), which are relevant to mercury transport.

Quantification of estuarine wetlands' imports/exports is difficult because suspended sediment and dissolved constituent concentrations and water discharge volumes vary continuously over numerous time scales: tidal cycles, events, river discharge, season, etc. In addition, the net flux of material onto or off a wetland is the relatively small difference between much larger gross fluxes associated with the incoming and outgoing waters of the flood and ebb tides (Murray and Spencer 1997; Ganju et al. 2005). Studies seeking to quantify tidal fluxes commonly sample discretely over a small number of tidal cycles and then extrapolate over longer time periods (Murray and Spencer 1997). This approach, however, can lead to large errors in the final flux estimates (Ganju et al. 2005), and it may miss or obscure important interactions between physical and biogeochemical processes (Bergamaschi et al. 2011). Continuous in situ measurements have the potential to address some of these problems.

High-resolution in situ measurements have been successfully used to measure constituent concentrations and fluxes in both tidal (e.g., Ganju et al. 2005; Downing et al. 2009; Bergamaschi et al. 2011) and non-tidal (Downing et al. 2008; Saraceno et al. 2009) systems. Turbidity measurements, a consequence of light scattering by particles, is commonly used as a proxy for fine sediment concentrations and often for $\mathrm{Hg}$ because sediment-associated $\mathrm{Hg}$ is the largest fraction of $\mathrm{Hg}$ in aquatic systems (Domagalski 2001). Similarly, fluorescent dissolved organic matter (FDOM) measurements have been used to quantify DOC concentrations (Saraceno et al. 2009), and filter-passing ("dissolved") $\mathrm{Hg}$ concentrations (Mitchell and Gilmour 2008). For this study, we hypothesized that, together, in situ measurements of turbidity and FDOM can serve as independent proxies for particulate and dissolved phases of mercury, providing an estimate of total $\mathrm{Hg}$ concentrations in estuarine and wetland waters. Understanding the role of wetlands in estuarine mercury cycling is particularly important in the San Francisco Bay Delta and estuary (SFE). Legacy Hg contamination from the 1860-1914 period of hydraulic mining has resulted in the transport of more than $6 \times 10^{8} \mathrm{~m}^{3}$ of mercury-laden sediment from the Sierra foothills into the estuary (Alpers et al. 2005). As a result, there are numerous fish consumption advisories and virtually the entire area is listed as impaired due to $\mathrm{Hg}$ (Domagalski 1998; Abu-Saba and Tang 2000). Presently, the SFE has $33 \mathrm{~km}^{2}$ of existing tidal wetlands (Jassby and Cloern 2000), and restoration of an additional $240 \mathrm{~km}^{2}$ has been proposed. A better understanding of $\mathrm{Hg}$ dynamics in SFE wetlands is important so restorations that minimize mobilization, transport, and methylation of mercury can be implemented.

As a contribution to this effort, we quantitatively assessed mercury exchange between Browns Island, a large tidal wetland, and the open waters of the San Francisco estuary. Our expectation and central hypothesis was that the wetland was a sink for $\mathrm{Hg}$, with $\mathrm{Hg}$ accumulation rates directly proportional to sediment accumulation rates. Because event-driven fluxes account for the majority of sediment flux onto the wetland, we expected these episodic events would also account for the majority of $\mathrm{Hg}$ flux. To test this hypothesis, we quantitatively estimated the flux of $\mathrm{Hg}$ in the two major tidal channels on Browns Island over a complete spring-neap tidal cycle in three different seasons using continuous in situ measurements of turbidity and FDOM. Discrete water samples were collected over a single tidal cycle during each deployment to relate the combination of turbidity and FDOM to the $\mathrm{Hg}$ concentration in unfiltered samples. From these calibration measurements, we developed and then applied a regression model to the longer-term in situ proxy data to produce a modeled time series of unfiltered $\mathrm{Hg}$ concentrations. These modeled concentrations were then combined with acoustic measurements of water discharge to calculate net exchange of mercury between the wetland and estuary and investigate the processes driving the exchange.

\section{Study Site}

Browns Island is a natural, tule-dominated, high stand marsh located in the upper San Francisco Estuary (SFE, Fig. 1). Tides near the island are mixed semidiurnal with a maximum spring tidal range of $1.8 \mathrm{~m}$ and a minimum neap tide range of $0.2 \mathrm{~m}$. The marsh plain is approximately $1 \mathrm{~m}$ above mean low low water; thus, the island is typically inundated during high spring tides. The regional water surface elevation varies seasonally due to variations in Sacramento River discharge, with higher river flows and therefore higher estuarine water levels in winter. 


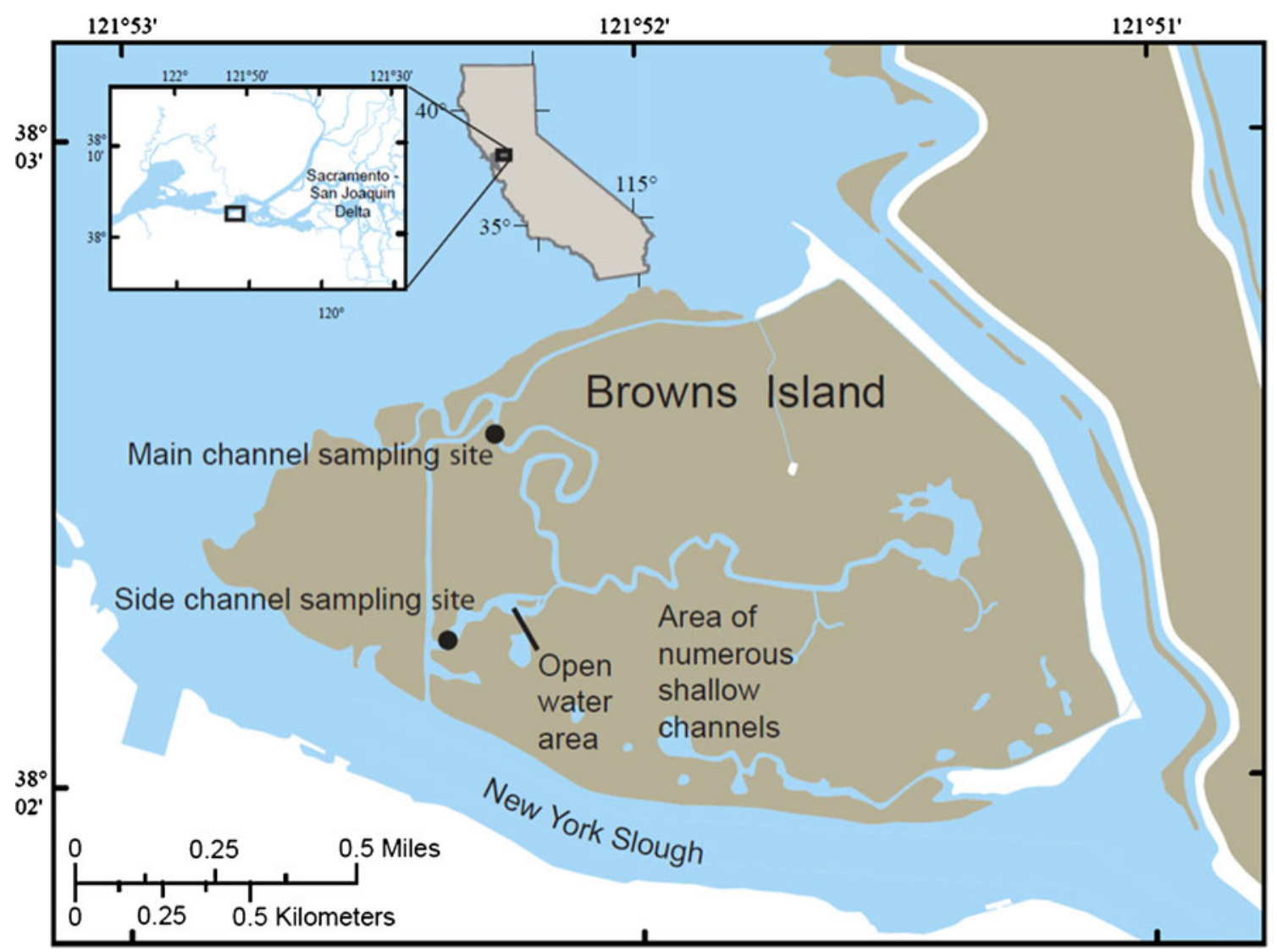

Fig. 1 Map of in situ deployment locations on Browns Island. Inset shows location of Browns Island in San Francisco Estuary

\section{Methods}

We conducted three seasonal field deployments of moored in situ instrument packages at two slough locations (Fig. 1). One site was in the north-facing main tidal channel that drains the majority of the island; the other was in the south-facing side channel, which drains a lower area on the south side of the island and is connected to the main channel through a few small openings. The instruments were sited at locations judged most suitable for discharge measurements because of their relatively well-defined channel cross-sections. The main channel was approximately $15 \mathrm{~m}$ wide and $3 \mathrm{~m}$ deep while the side channel was approximately $8 \mathrm{~m}$ wide and $2 \mathrm{~m}$ deep at the instrument locations. High-resolution in situ optical and acoustic measurements were collected over at least a complete springneap tidal cycle during each season: spring (13 April-04 May 2005), fall (5 October-26 October 2005), and winter (13 January-04 February 2006). Depth-averaged water velocity and water depth in the channels were measured throughout.

Water samples were collected for dissolved organic carbon (DOC) and $\mathrm{Hg}$ analysis every 1 to $3 \mathrm{~h}$ over a 26-h tidal cycle at both main and side channel instrument locations during each deployment. The timing of the sampling corresponded to the times of maximum predicted tidal range during the seasonal deployment period. Since considerable cross-section variability can occur in tidal channels (Ganju et al. 2005), we sampled at the instrument locations across the channel to ensure that the index measurement made by the instruments in the center of the channel was calibrated to the integrated concentration across the channel rather than just a point mid-channel, which may not fully represent constituent flux. Five depthintegrating vertical casts were made at equal discharge increments (EDI) across the channel with an isokinetic D-77 sampler fitted with a 1/4-inch Teflon nozzle and a 3-L Teflon bottle (Edwards and Glysson 1999; Ganju et al. 2005; Downing et al. 2009), resulting in a single, discharge-weighted composite sample at each calibration time point.

A total of 30 discrete water samples were collected at the main-channel site; 25 were collected in the side channel. An instrument failure occurred during the spring side channel sampling, and thus no calibration samples were available for the side-channel site during the spring deployment period. All samples were analyzed for whole-water (unfiltered) total mercury concentration (UTHg). Thirteen samples from the springtime main channel were analyzed for filtered total mercury concentration (FTHg). Particulate total mercury concentration $(\mathrm{PTHg})$ was derived as the difference between the $\mathrm{Hg}$ concentrations in the unfiltered and filtered samples. 
Waters to be analyzed for DOC content were decanted immediately and gravity-filtered through a $0.3 \mu \mathrm{m}$ glass fiber filter (Advantec MFS) into amber glass vials. The filtered water samples were then transported on ice, stored chilled $\left(<4{ }^{\circ} \mathrm{C}\right)$, and analyzed within $24 \mathrm{~h}$. Filters containing suspended particulate matter were wrapped in aluminum foil in the field and then frozen for storage upon arrival at the laboratory.

For mercury sampling, a slightly modified version of Environmental Protection Agency (EPA) Method 1669 (U.S. Environmental Protection Agency 1996) was used. Samples were collected with mercury-clean techniques using acid-washed Teflon bottles and nozzles. One aliquot of each sample was collected for whole water (unfiltered) analysis. For filtered sampling, a second aliquot was filtered using a specialized Hg-clean Teflon filtration system $(0.45 \mu \mathrm{m}$, No. 12178, Pall; Puckett and Buuren 2000). Filtration was typically conducted immediately onboard the boat. On occasion, when onboard filtering was not possible, samples were filtered in the laboratory within $24 \mathrm{~h}$ of collection. Samples were preserved with trace metal grade $\mathrm{HCl}$ immediately following aliquot processing and were stored chilled $\left(<4{ }^{\circ} \mathrm{C}\right)$ until analysis. Field blank values were determined by using the same sampling apparatus and procedure to collect and process deionized water in the field.

\section{Laboratory Analyses}

Bulk dissolved organic matter (reported as DOC) in the filtered water samples was measured by high-temperature catalytic oxidation (Shimadzu TOC-5000A total organic carbon analyzer; Bird et al. 2003). The accompanying particle-laden filters were dried and weighed to obtain suspended sediment concentrations (SSC) gravimetrically according to ASTM Standard Test Method D 3977-97B, as recommended for fine and organic particulate samples (Gray et al. 2000). Organic content of the particulates (POC) was measured as loss-on-ignition (LOI) from the SSC samples, following standard method ASTM D2974.

Total $\mathrm{Hg}$ (THg) concentrations in the unfiltered and filtered water samples were determined using EPA method 1631e (U.S. Environmental Protection Agency 2002). The samples were oxidized using bromine monochloride $(\mathrm{BrCl})$ solution until all $\mathrm{Hg}$ was converted to $\mathrm{Hg}$ (II), as indicated by preservation of the $\mathrm{BrCl}$ color. The remaining $\mathrm{BrCl}$ was then reduced with hydroxylamine. Subsequently, an aliquot of sample was reduced to $\mathrm{Hg}^{0}$ using $\mathrm{SnCl}_{2}$ in a bubbling purge-and-trap system fitted with a gold trap. The gold trap was then pyrolized to release the $\mathrm{Hg}^{0}$ for detection by cold vapor atomic absorbance spectrophotometry. Based on repeated laboratory replicate measurements of $\mathrm{THg}$ in a known low-THg substrate, the method detection limit for the analysis was assessed to be $0.2 \mathrm{ng} \mathrm{L}^{-1}$. Field blank values were below the method detection limit.

\section{In Situ Measurements and Data Processing}

Fluorescent dissolved organic matter (FDOM) was measured in situ using a WETStar fluorometer, with excitation centered at $370 \mathrm{~nm}$ and emission centered at $460 \mathrm{~nm}$ (WET Labs). A conductivity-temperature-pressure sensor (SBE37MicroCAT, Sea-Bird Electronics) was also mounted on the package, as was an instrument sonde to measure water temperature, $\mathrm{pH}$, and turbidity as backscatter at $860 \mathrm{~nm}$ (DS4, Hydrolab). The instruments were fastened within an anchored stainless steel cage, with sample intakes for the flow-through instruments located approximately $1 \mathrm{~m}$ above the channel bottom. Every $30 \mathrm{~min}$, data were collected for a 2 min interval. Detailed methods and protocols are provided in Downing et al. (2009). Turbidity data were unavailable for 1 week of the spring deployment due to instrument failure; for this period, turbidity was estimated from the transmission channel of a WET Labs ac-9 in situ spectrophotometer (Bergamaschi et al. 2011).

Continuous water velocities (index velocities) were measured at the center of the tidal channel, close to the chemical/ optical sensor package, using an upward-looking acoustic Doppler velocity meter (ADVM; Sontek Argonaut XR, Sontek/YSI) mounted in a low-profile cage as described by Ganju et al. (2005). Depth-averaged water velocity and water depth above the unit were measured every $15 \mathrm{~min}$ for 6 min. For calibration purposes, channel cross-section and variation in current velocity were determined by conducting a moving-boat survey at each site with a downward-looking acoustic Doppler profiler over a day of maximum spring tides during each deployment period. These data permitted us to relate the channel cross-sectional area to water depth and also the average water velocity to the index velocity at every tidal phase. These methods and their associated errors are fully described in Ganju et al. (2005).

Data from the in situ optical instruments were binned to a 30 -min interval by averaging over the last $10 \mathrm{~s}$ of each $2 \mathrm{~min}$ sampling period; these data were then interpolated to correspond temporally with the accompanying 15 min discharge measurements (Downing et al. 2009). Measurement baselines were corrected if necessary using a simple linear correction between service intervals (Wagner et al. 2006). Gaps in the time series due to service breaks were filled via cubic spline interpolation.

Wind, precipitation, and evapotranspiration data were obtained from the Twitchell Island, Concord, and Hastings Tract sites of the California Irrigation Management Information System (CIMIS) network (www.cimis.water.ca.gov).

\section{Concentration and Flux Modeling}

Unfiltered total mercury (UTHg) concentration time series for all deployments were developed from a partial least 
squares (PLS) regression model (The Unscrambler, Camo Software) that related the in situ center channel "index" measurements of turbidity and FDOM to the accompanying horizontally and vertically integrated $\mathrm{THg}$ concentrations obtained from the EDI water samples collected across the channel section. PLS modeling was chosen to reduce any potential effects of collinearity among the two variables (Esbensen et al. 2002). Turbidity and FDOM values were normalized by their standard deviations to equally weight the concentration ranges of the two variables during the modeling process. The resulting models were fully crossvalidated by step-wise sample exclusion, and a single outlier identified by the software was removed to improve model quality. This method of validation is recommended for cases in which a small number of samples are available for model development (Esbensen et al. 2002). Total validation error was calculated as the sum of the squares of the differences in all cross-validation submodels. The final model explained $94 \%$ of the variance in the discrete THg data (Fig. 2); validation error was within $7 \%$ of the predictions.

Channel discharge was calculated for each 15 min interval as the product of the cross-sectional area, which was dependent upon tidal stage and the average water velocity across the cross-section, as described in Downing et al. (2009) and Ganju et al. (2005). Cumulative water fluxes did not balance for the periods over which the fluxes were calculated with per-tide imbalances being largest during

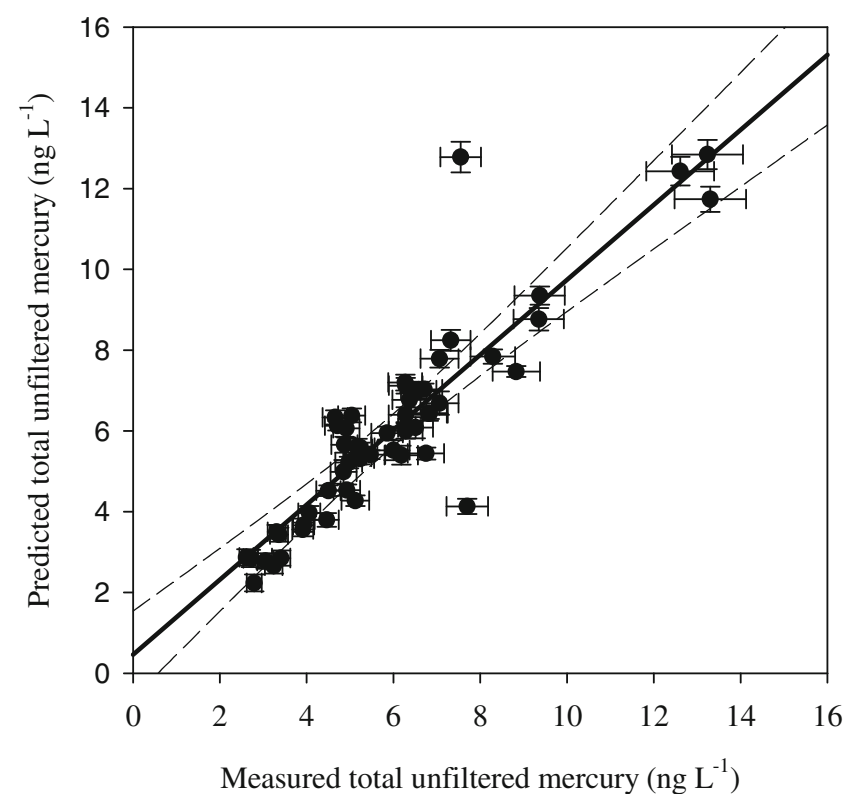

Fig. 2 Comparison of measured and modeled values for unfiltered total Hg (UTHg) in nanograms per liter. Horizontal bars show analytical error in measured values; vertical bars show error of prediction for the model (see Methods section). The solid line shows the regression between the predicted and measured values; the dashed lines indicate the range over which values predicted by the regression would fall with $95 \%$ confidence $(P<0.05$; Sigma Plot, Systat Software, Inc.) spring tides. This pattern suggests that water from the spring high tides likely at times drains not only through the large sloughs but also escapes across the marsh plain or ebbs partially through smaller channels that are concentrated on the south side of the island (Fig. 1). The cumulative water discharge was flood-positive for spring and fall and floodnegative for winter. For the winter deployment, the median imbalance was $-9 \%$; for the fall, it was $7 \%$; and in the spring, it was $5 \%$.

The unfiltered total mercury flux for each 15 -min interval was calculated over a single complete spring-neap cycle for each deployment period as the product of water flux and UTHg concentration. For the purpose of calculating UTHg fluxes, we forced closure in the water budget mass balance over the period of calculation for each deployment period (Downing et al. 2009). Water used to close the mass balance was assigned UTHg properties of the influent channel waters during winter and of the outgoing side channel during spring and fall. UTHg concentrations of the smaller, shallower, lower-volume side-channel site were judged to better represent the waters likely ebbing through small distributary channels. Based on precipitation and reference evapotranspiration values obtained from nearby CIMIS meteorological stations, as well as earlier measurements at a nearby similar tule wetland (Drexler et al. 2004), we considered the effects of precipitation and evapotranspiration to be negligible in terms of contributions to the water budgetthey represent water volumes less than $1 \%$ of the tidal exchange volume.

\section{Error Estimation}

We estimated the total error in the flux estimates as the accumulation of the error inherent in each individual measurement by taking the square root of the sum of the squares of the individual contributing errors, as described in Ganju et al. (2005). All methods and measurements have inherent error. The EDI sampling method, for example, cannot precisely provide measurements of the channel-averaged constituent concentrations because of lateral and vertical concentration variability not captured by the sampling strategy (Ganju et al. 2005). This error was estimated to be $9 \%$ (Ganju et al. 2005). The largest other sources of error were the error inherent in the $\mathrm{THg}$ measurement method (average $6.2 \%$ ), the water flux calculations (6\%; Ganju et al. 2005), and the partial least squares regression model $(\sim 7 \%)$. For the UTHg concentration model (Fig. 2), the root mean square error of prediction (RMSEP) averaged $2 \%$ of the observed value. We assumed the individual errors were not correlated. The error in the flux calculation was thus estimated to be $27 \%$, similar to the error reported for estimates of Browns Island sediment flux (27\%; Ganju et al. 2005). 


\section{Results}

For the unfiltered water samples collected across all seasons, total mercury (UTHg) concentrations in the Browns Island main channel (Fig. $3 ; n=30$ ) ranged from 3.4 to $13.3 \mathrm{ng} \mathrm{L}^{-1}$; the mean concentration was $6.5( \pm 2.6) \mathrm{ng} \mathrm{L}^{-1}$. Side channel concentrations (Fig. $4 ; n=25$ ) were generally lower, ranging

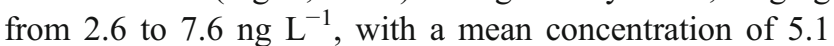
$( \pm 1.7) \mathrm{ng} \mathrm{L}^{-1}$. Some variation by season was observed, with the one-tidal-cycle concentration range being smallest in the winter. Spring-deployment UTHg concentrations ranged from 4.6 to $13.3 \mathrm{ng} \mathrm{L}^{-1}$, with a mean of $6.2( \pm 2.6) \mathrm{ng} \mathrm{L^{-1 }}$; fall-deployment values ranged from 2.6 to $13.2 \mathrm{ng} \mathrm{L}^{-1}$, with a mean of $5.2( \pm 2.9) \mathrm{ng} \mathrm{L^{-1 }}$; and winter deployment concentrations ranged from 4.9 to $9.4 \mathrm{ng} \mathrm{\textrm {L } ^ { - 1 }}$, with a mean of $6.6( \pm 1.1) \mathrm{ng} \mathrm{L}^{-1}$.

Most of the mercury was associated with the particulate phase. Concentrations of UTHg in the tidal channels were positively correlated with suspended sediment (SSC; $r=0.88 ; p<0.0001$; Table 1) and particulate organic carbon concentrations (POC; $r=0.75 ; p<0.0001$; Table 1). A weaker but still significant positive correlation was observed between UTHg and particle-associated methylated mercury (PMeHg; $r=0.56 ; p<0.0001$; Table 1).

Total mercury concentrations at Browns Island are similar to those previously reported for the Sacramento River, which enters the head of the estuary just to the east (3-10 ng L ${ }^{-1}$ at the 75th percentile; Domagalski 2001), with most of this mercury associated with the particulate phase. The fraction of Browns Island UTHg that was methylated ranged from $0.5 \%$ to $4.1 \%$, with a mean of $2.1( \pm 0.9) \%$ (Bergamaschi et al. 2011). These values are similar to those of lower Sacramento River waters (average $\sim 1.5 \%$; Domagalski 2001) but are much higher than in the surface sediments of nearby Grizzly and Honker Bays $(<0.2 \%$; Conaway et al. 2003).

For the available FTHg measurements, all from the springtime main channel $(n=13)$, concentrations ranged from 1.0 to $1.9 \mathrm{ng} \mathrm{L}^{-1}$, and the mean concentration was $1.4( \pm 0.3) \mathrm{ng} \mathrm{L}^{-1}$. For these same samples, UTHg concentrations ranged from 4.5 to $13.3 \mathrm{ng} \mathrm{L}^{-1}$, with a mean value of $6.6( \pm 2.6) \mathrm{ng} \mathrm{L}^{-1}$. The particulate $\mathrm{Hg}$ (PTHg) concentrations, determined by difference, ranged from 3.0 to $12.3 \mathrm{ng} \mathrm{L}^{-1}$, with a mean value of 4.8 $( \pm 2.8) \mathrm{ng} \mathrm{L}^{-1}$. On average, $\sim 70 \%$ of the $\mathrm{THg}$ was in the particulate phase and $\sim 30 \%$ was in the filter-passing fraction. Highest concentrations of FTHg were observed coincident with low water (ebb) and lowest concentrations were seen at times of highest water (near maximum flood). Variation in DOC explained $56 \%$ of the variation in FTHg for these samples (Table 1).

Correlations between UTHg and POC and between UTHg and SSC for the spring main channel samples were
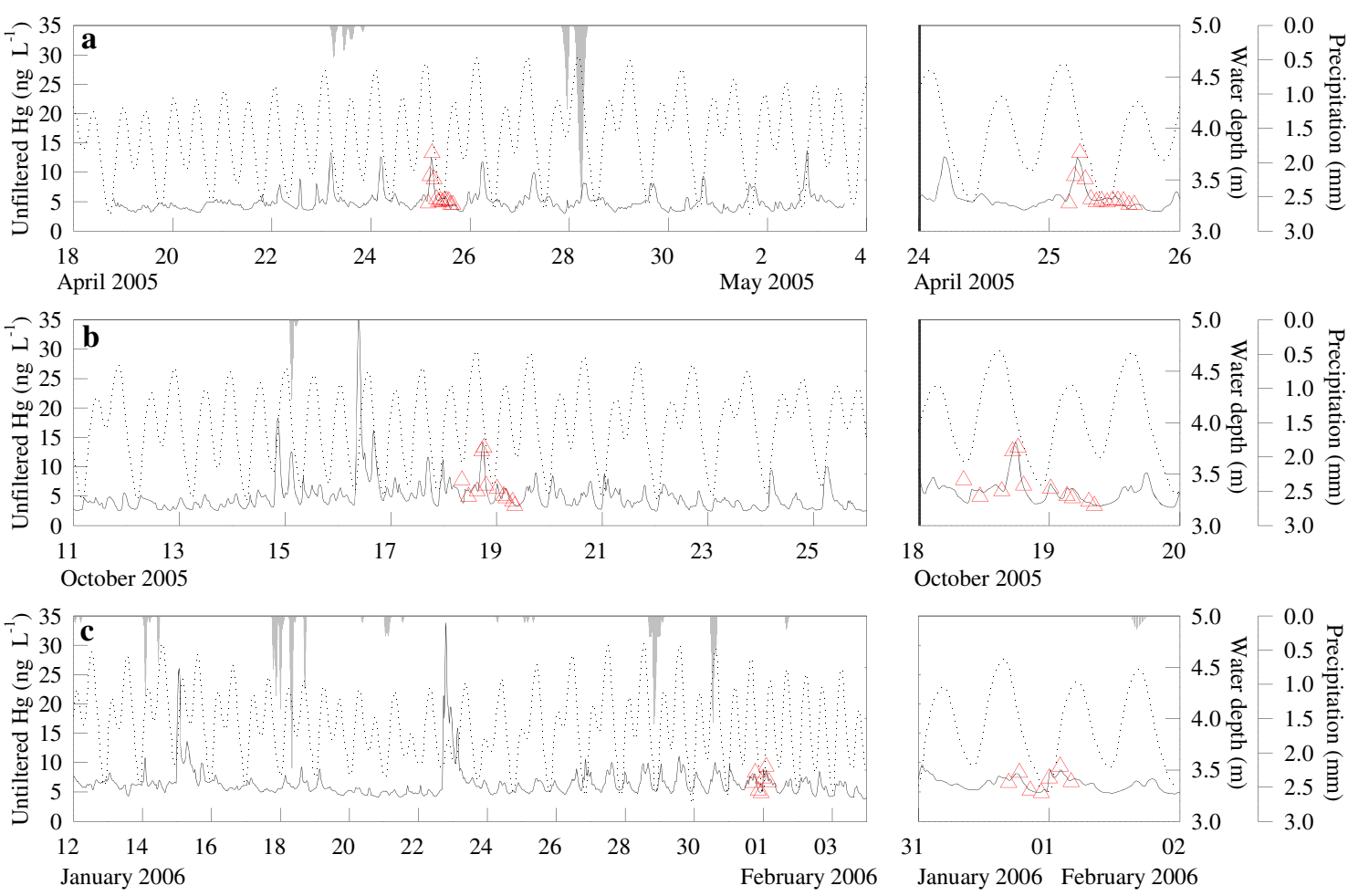

Fig. 3 Modeled time series of unfiltered total mercury concentration (UTHg, solid line) in the Browns Island main channel during a spring, b fall, and c winter deployments. The red triangles show concentrations measured in the discrete water samples. Water depth is indicated by the dashed line; precipitation is shown as gray bars 

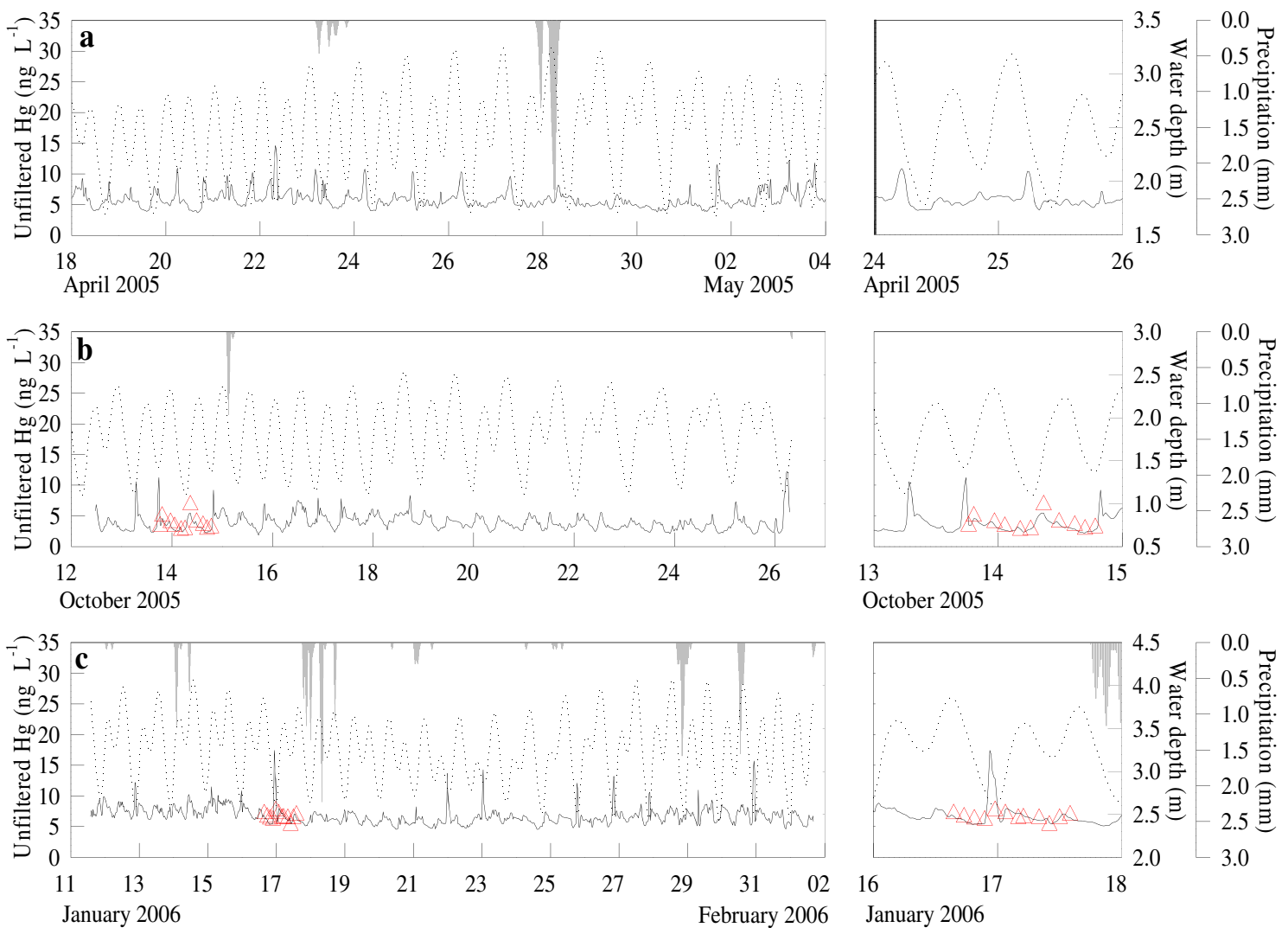

Fig. 4 Modeled time series of unfiltered total mercury (UTHg, solid line) in the Browns Island side channel during the a spring, $\mathbf{b}$ fall, and $\mathbf{c}$ winter deployments. The red triangles show concentrations measured

much stronger $(r=0.98)$ than for the data set as a whole $(r=0.75$ and 0.88 ; Table 1$)$. PTHg exhibited similarly strong relationships with these same parameters $(r=0.98)$, again indicative of the high fraction of UTHg associated with particles.

The discrete-sample measurements and their in situ analogues exhibited similar patterns of variability (Table 1). In situ turbidity was significantly correlated with UTHg $(r=0.88)$, and in situ FDOM was significantly correlated with FTHg $(r=0.75)$. As with the particle-specific parameters measured directly (POC and SSC), the correlation between UTHg and in situ turbidity was stronger for the springtime main channel $(r=0.97)$ than for the data set as a whole $(r=0.88)$. These relatively robust correlations between particle-associated and filter-passing mercury and their in situ counterparts, turbidity and FDOM, gave us confidence that these in situ measurements could be used to reliably model $\mathrm{Hg}$ concentrations over the course of our spring-neap deployment periods (Figs. 3 and 4). In situ measurements of turbidity alone explained $77 \%$ of the UTHg variability observed across all samples. Adding FDOM produced a PLS model of turbidity and FDOM together that explained $94 \%$ of the observed variability in UTHg (Fig. 2). This PLS model was applied to the in the discrete water samples Water depth is indicated by the dashed line; precipitation is shown as gray bars. No water samples were collected during the spring deployment

continuous time series of in situ turbidity and FDOM to obtain modeled UTHg concentrations in each tidal channel for each season (Figs. 3 and 4). As observed in the discrete water samples, modeled baseline concentrations were higher in spring and winter $\left(\sim 5 \mathrm{ng} \mathrm{L}^{-1}\right)$ than in the fall $\left(\sim 3 \mathrm{ng} \mathrm{L}^{-1}\right)$. Occasional turbidity spikes in the times series resulted in high model-predicted UTHg concentrations $\left(\sim 25-35 \mathrm{ng} \mathrm{L}^{-1}\right)$ coincident with strong northerly winds during the fall and winter deployments.

These high modeled UTHg concentration values during wind events are outside the model calibration; calibration sampling for the concentration model did not encompass the periods of strong northerly winds (Figs. 3 and 4). Accordingly, the highest modeled concentrations of UTHg, which lie outside the model's calibration range, cannot be considered quantitative; they are presented here for the heuristic purpose of evaluating the potential relative magnitude of the various different processes affecting flux. However, previous work at Browns Island has demonstrated that high in situ turbidity values in the range measured during these events are proportional to suspended sediment concentrations (Ganju et al. 2005). Also, the sediment mercury concentrations predicted by the model for these periods is approximately $200 \mathrm{ng} \mathrm{g}^{-1}$, with the presumptive source 
Table 1 Correlation coefficients for mercury and selected parameters

\begin{tabular}{lllll}
\hline & \multirow{2}{*}{ All samples } & \multicolumn{2}{l}{ Spring main channel samples } \\
\cline { 3 - 5 } & UTHg & UTHg & FTHg & PTHg \\
& $n=55$ & $n=13$ & $n=13$ & $n=13$ \\
\hline UTHg & - & - & -0.33 & $\mathbf{0 . 9 9}$ \\
FTHg & nd & -0.33 & - & -0.42 \\
PTHg & nd & $\mathbf{0 . 9 9}$ & -0.42 & - \\
UMeHg & $\mathbf{0 . 5 0}$ & $\mathbf{0 . 7 1}$ & -0.23 & $\mathbf{0 . 7 0}$ \\
FMeHg & 0.18 & -0.41 & $\mathbf{0 . 7 9}$ & -0.48 \\
PMeHg & $\mathbf{0 . 5 6}$ & $\mathbf{0 . 7 9}$ & -0.59 & $\mathbf{0 . 8 2}$ \\
DOC & 0.11 & -0.31 & $\mathbf{0 . 7 5}$ & -0.37 \\
POC & $\mathbf{0 . 7 5}$ & $\mathbf{0 . 9 8}$ & -0.33 & $\mathbf{0 . 9 8}$ \\
NO 3 & 0.29 & $-\mathbf{0 . 7 2}$ & 0.31 & 0.37 \\
SSC & $\mathbf{0 . 8 8}$ & $\mathbf{0 . 9 8}$ & -0.38 & $\mathbf{0 . 9 8}$ \\
Turbidity & $\mathbf{0 . 8 8}$ & $\mathbf{0 . 9 7}$ & -0.41 & $\mathbf{0 . 9 7}$ \\
FDOM & 0.13 & -0.30 & $\mathbf{0 . 7 5}$ & -0.37 \\
DO & 0.10 & 0.07 & $-\mathbf{0 . 6 2}$ & 0.13 \\
\hline
\end{tabular}

Entries shown in bold are significant at $P<0.001$. Methylmercury data are from Bergamaschi et al. (2011)

UTHg total mercury concentration in unfiltered water samples; FTHg concentration of total mercury in filter-passing fraction; $P T H g$ particulate mercury concentration, calculated as the difference between the total $\mathrm{Hg}$ in unfiltered and filter-passing fractions. $\mathrm{FMeHg}$ concentration of methyl mercury in filter-passing sample; $\mathrm{UMeHg}$ methyl mercury concentration in unfiltered samples; $\mathrm{PMeHg}$ concentration of particulate methyl mercury, calculated as the difference between $\mathrm{UMeHg}$ and FMeHg. DOC dissolved organic carbon concentration; $P O C$ particulate organic matter concentration as carbon. SSC suspended sediment concentration. FDOM fluorescent dissolved organic matter. $D O$ dissolved oxygen concentration

being local re-suspension of sediments from the nearby bar in Suisun Bay (Fig. 1). This model-predicted value is similar to sediment mercury concentrations reported by Conaway

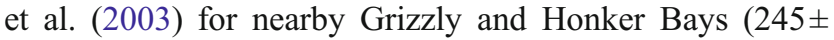
$25 \mathrm{ng} \mathrm{g}^{-1}$ ), which are sub-embayments of Suisun Bay.

The final step of the data analysis was to calculate the cumulative UTHg fluxes for each deployment period using the modeled UTHg concentrations (Figs. 3 and 4) in combination with water discharge data (Fig. 5). Although the fluxes during high winds can only be estimated based on this particular data set owing to the absence of calibration measurements during these events, the sediment concentrations on which the flux calculations are based are in the range of values reported by Conaway et al. (2003).

Model-predicted fluxes were similar for the three deployment periods and were not appreciably different from zero when integrated over a full spring-neap cycle (Fig. 5). Small, persistent off-wetland (negative) UTHg fluxes occurred during large spring tides, and occasional on-wetland (positive) fluxes accompanied strong northerly wind events. Calculated fluxes for the winter and fall deployment periods were net on-island, in the range of $0.05 \mathrm{~g} \mathrm{Hg}$. The calculated flux in springtime was net off-island, approximately $-0.07 \mathrm{~g}$ Hg. All calculated spring-neap net fluxes are smaller than observed single-tide fluxes and are also within the error of the method.

\section{Discussion}

Many processes occurring over different time scales affected the $\mathrm{Hg}$ dynamics over the course of the study. For example, event-related, tide-related, and low-level random concentration variability were all apparent in the time series (Figs. 3 and 4). The greatest excursions of modeled concentration were associated with spikes of high turbidity that coincided with strong northerly wind events (fall and winter), primarily affecting the main-channel site (Fig. 3). During the strongest events, which occurred on October 16 and January 22, modeled UTHg concentrations jumped $\sim 30 \mathrm{ng} \mathrm{L}^{-1}$ over baseline values. Elevated northerly winds have been previously documented as important agents of sediment resuspension and transport in the Browns Island area (Ganju et al. 2005). A significant increase in modeled on-island (positive) UTHg flux accompanied these strong fall and winter sediment resuspension events (Fig. 5).

The timing of the strong winds relative to tidal stage appeared to affect the magnitude of these event-driven fluxes. For instance, the high northerly winds of October 16 coincided with a rising tide, producing a $0.1-\mathrm{g}$ increase of the on-island flux (Fig. 5). In contrast, the January 22 wind event of a similar magnitude coincided with a falling tide, resulting in a smaller on-island flux increase (approximately $0.05 \mathrm{~g})$.

Outside these episodic wind-driven sediment resuspension events, the majority of the modeled UTHg concentration variation was associated with the systematic rise and fall of the tides (Figs. 3 and 4). Both the main- and sidechannel sites exhibited tide-associated peaks in modeled UTHg concentration, with maxima tending to occur near low water (Figs. 3 and 4). Peak magnitudes varied according to location, season, and timing within the spring-neap cycle. For example, peak magnitudes were greater in the main channel than in the side channel (Figs. 3 and 4), with the greatest systematic concentration variation seen during the spring deployment period in the main channel. This may be because higher water velocities of the main channel are more effective at entraining mercury-laden material from the channel bottom. Neap periods of the lunar cycle generally corresponded to lower water velocities and diminished modeled UTHg concentration variability.

The timing of the winds relative to the tidal cycle influenced not only major event-driven fluxes but also smaller tidally associated fluxes. During the fall deployment, for 

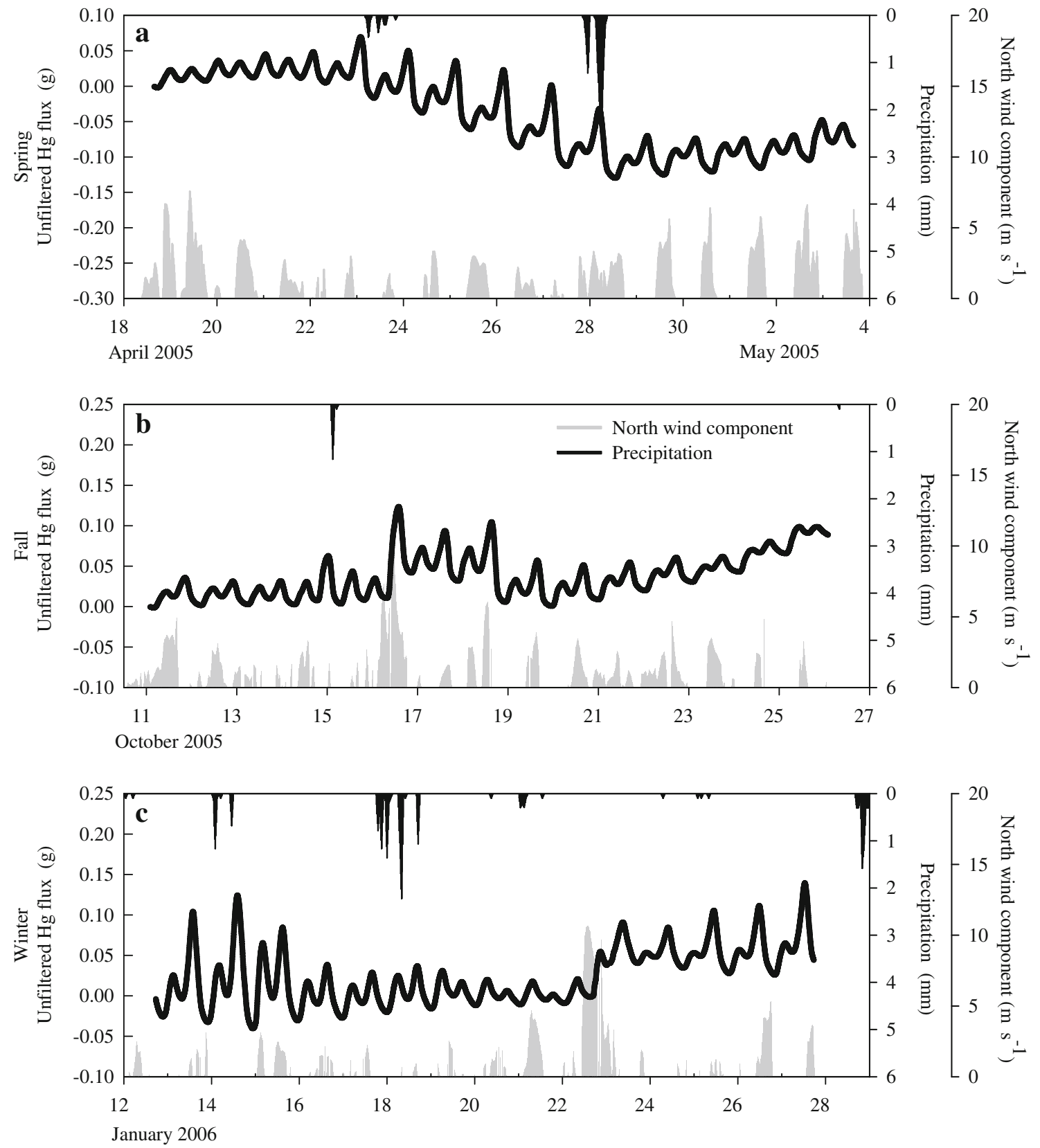

Fig. 5 Cumulative net fluxes of unfiltered total mercury (UTHg) for a full spring-neap cycle on Browns Island (both channels) for a spring, $\mathbf{b}$ fall, and $\mathbf{c}$ winter deployments. Descending black bars show precipitation. Gray bars show the northerly component of the wind. Off-island flux is defined as negative

net flux occurred outside the major wind resuspension event of January 22.

The source of mercury in the water column varied through time, depending on hydrologic and meteorological forcing and the effects of local geomorphic features. The main channel mouth exchanges water with the open estuary across a broad, shallow tidal bar, the side channel exchanges water directly with a deep (>15 m) river channel (Fig. 1). The similarity in contemporaneous baseline concentrations between the two channels (Figs. 3 and 4) suggests that both 
channels are, under baseline conditions, responding to a common source of influent water and UTHg, rather than more localized, channel-specific sources. The likely source of the baseline mercury is the sediment-laden waters of the Sacramento and San Joaquin rivers, which flow into the head of the estuary east of Browns Island. The higher spring and winter baseline UTHg concentrations are attributable to elevated turbidity associated with higher winter flows in both rivers (California Department of Water Resources 2010).

During strong wind events, local UTHg sources may predominate. The strong northerly winds of October 2005 and January 2006, for example, caused large spikes in measured turbidity and therefore modeled UTHg concentration-but only in the north-facing main channel, not the south-facing side channel. The bar outside the main channel seems to have served as a local source of resuspended sediment and, presumably, accompanying $\mathrm{Hg}$.

In contrast, the source of the filter-passing $\mathrm{Hg}$ fraction seems to be the wetlands themselves. During the spring deployment, elevated FTHg concentration values were observed throughout the ebb of the sampled tidal cycle, coincident with periods of elevated FDOM (i.e., elevated DOC). Because DOC can solubilize Hg (Amirbahman et al. 2002), it is likely that the high-DOC waters draining from the marsh had facilitated the repartitioning of sedimentaryphase $\mathrm{THg}$ into the colloidal or dissolved phases, thus accounting for the elevated concentrations of filter-passing mercury. FTHg was also correlated with FMeHg $(r=0.79$; Table 1), consistent with the idea that solubilization by DOC promotes transport and methylation.

Peaks in observed FDOM (i.e., DOC) values also accompanied the strongest of the small, systematic off-wetland UTHg fluxes that occurred during large spring tides (Fig. 5). This pattern is consistent with the notion that the DOC-rich waters draining the marsh may have promoted solubilization and mobilization of previously deposited particulate Hg. Resuspension of finer sedimentary particles or particles high in organic matter content, both of which have been associated with higher $\mathrm{THg}$ content in the SFE (Conaway et al. 2003), could also have contributed to the spring-tide off-marsh exports.

The implication of these collective observations is that on-island UTHg flux at Browns Island seems to be largely particle-associated and event-driven-dependent on the magnitude of the winds, their timing with respect to the tides, and the orientation of channel inlets relative to wind direction. Net off-island UTHg flux seems to be associated primarily with the export of filter-passing mercury and is strongest during periods of large spring tides. High current velocities also encourage $\mathrm{Hg}$ transport- the systematic concentration fluctuations that accompanied the tides (Fig. 3) were of greatest magnitude during times of peak water velocity, perhaps because of entrained fine, organic-rich sediment. The positive-negative net flux imbalance is slight, so even relatively minor forcing changes - such as the orientation of tidal channels or whether afternoon breezes align with a rising or falling tide - may shift the wetland from sink to source or vice versa.

Wetlands, particularly estuarine wetlands, are most often thought to be sedimentary sinks and thus presumptive sinks for total Hg (Ganju et al. 2005; Selvendiran et al. 2008; Shanley et al. 2008). Net on-wetland flux of sediment has been previously documented at Browns Island (Ganju et al. 2005), and we therefore expected to observe net on-wetland fluxes of $\mathrm{Hg}$ as well. That we found no appreciable net onwetland flux of $\mathrm{Hg}$ is contrary to our hypothesis that an onisland flux of sediment would have a proportional flux of associated $\mathrm{Hg}$ which is retained by the wetland. It appears instead that for Browns Island, and perhaps other estuarine wetlands as well, episodic deposition-related acquisitions of particle-associated mercury were offset by persistent tidally driven exports of filter-passing mercury. The large concentration excursions (spikes) driven by major wind events are much larger than the smaller systematic concentration variations associated with astronomical tides and tidal currents (Figs. 3 and 4). But at Browns Island, over the timescale of a spring-neap cycle, the fluxes driven by these opposing forces-large, pulsed on-island fluxes and smaller but more persistent off-island fluxes - are roughly equivalent.

A better understanding of the numerous physical processes that influence mercury fluxes helps inform and guide wetland restoration efforts in SFE and elsewhere. Our observations at Browns Island, for example, indicate that tidal exchange volume, water velocities, channel orientation, and proximity to a sediment source are all important determinants of $\mathrm{Hg}$ flux. Also, as pointed out previously (Bergamaschi et al. 2011), a sill that limits wetland drainage can restrict export of wetland-derived material. Although Browns Island, an established tidal wetland, did not appear to be a significant sink of $\mathrm{Hg}$ for the period of the study, it is possible that newly restored wetlands would not be in sediment equilibrium and would thus act as sediment (and presumably $\mathrm{Hg}$ ) sinks until equilibrium is achieved.

The results of this study also confirm the importance of using continuous, longer-term measurements to help elucidate mercury dynamics. Measurements over a single tidal cycle or a small number of cycles can significantly bias flux estimates. For example, if Browns Island cumulative fluxes for the winter deployment are calculated by simple extrapolation from the single tide over which discrete samples were collected (Figs. 3 and 4), the apparent cumulative 3-week flux would be $>0.5 \mathrm{~g}$ UTHg off the island; the estimated annual flux would be $>15 \mathrm{~g}$ off-island. In contrast, calculations based on our continuous measurements over the entire spring-neap cycle yield a 3-week flux estimate near zero (Fig. 5), suggesting that annual fluxes are minimal. 
Still, there is no assurance that the deployments in this study adequately represent the full annual cycle either. To better elucidate fluxes of mercury in tidal systems, continuous proxy measurements should be undertaken over as long a time period as possible. Continuous, high-resolution measurements will help capture episodic, short-term events or processes that might otherwise be missed by lowerresolution sampling. Longer-term deployments will help improve estimates of fluxes and detect trends or other effects of biogeochemical processes that may be evident only over longer periods.

One key result of this study is a demonstration that estimating mercury fluxes in tidal estuaries or other dynamic environments is a practical undertaking. The parameters used to develop the concentration model used in this study - turbidity and FDOM - are relatively easily and commonly measured. Importantly, they are also mechanistically related to the underlying drivers of $\mathrm{Hg}$ fluxes in this tidal wetland (Domagalski 2001; Ravichandran 2004). Other, more complex systems may require measurement of additional parameters to adequately model UTHg concentrations, but for many settings, it seems likely that a relatively small number of direct measurements may be extended over space or time by using proxy measurements. When doing so, it is axiomatic that the proxy measurements be mechanistically related to $\mathrm{Hg}$ concentration through the processes under study rather than simply empirical. Further, calibrations required to develop proxy:concentration relationships are likely site-specific, and perhaps even seasonor storm-specific; the underlying relationships among the directly measured and proxy parameters must be established specifically for the particular circumstances and goals of any given study, and verified over the life of the study.

The utility of continuous measurements of this type can be expanded considerably through the simultaneous deployment of relatively inexpensive complementary sensors. For example, particle concentration and size distribution can be estimated from acoustic backscatter and attenuation data obtained from the same equipment used to measure water velocities (Gartner 2004). Also, continuous multiwavelength fluorescence, light absorbance, and optical attenuation can also be measured. Together, these measurements would provide a more complete picture of particle and dissolved constituent properties (Spencer et al. 2007; Pellerin et al. 2009; Bergamaschi et al. 2011), and thus better links to processes governing mercury cycling. These relatively inexpensive, multi-pronged approaches provide a previously unimaginable ability to relate biogeochemical processes to physical forcings, sedimentological events, hydrologic flow paths, and geomorphological features, thus aiding the development of more accurate predictive models to help guide environmental management, mercury mitigation, and wetland restoration efforts.

\section{Conclusions}

Although wetlands are generally considered to be sinks for sediment and associated mercury, the Browns Island wetland was not a measurable source or sink over the period of the study. Instead, large, episodic on-island fluxes of sedimentary $\mathrm{THg}$ associated with elevated wind events were substantially offset by the gradual, tidally driven export of UTHg from the wetland. The largely particle-associated onisland flux of UTHg was highest during strong winds coincident with flood tides, appeared to depend on the orientation of the tidal channel with the wind, and was apparently from a source proximal to the wetland. Exports off-island were highest during large spring tides, when ebbing waters relatively enriched in FDOM, DOC, and filter-passing mercury drained from the marsh into the open waters of the estuary.

This study demonstrates that important interactions between physical and biogeochemical processes are evident through longer term monitoring of $\mathrm{Hg}$ dynamics in tidal systems. A greater understanding of how physical processes affect $\mathrm{Hg}$ dynamics in tidal wetlands may help the design and implementation of wetland restorations. For example, our results suggest that tidal exchange volume, water velocities, channel orientation, and proximity to a sediment source are all important determinants of $\mathrm{Hg}$ flux, and all relevant to wetland design and construction.

In situ measurements of turbidity and FDOM-representative of particle-associated and filter-passing $\mathrm{Hg}$, respectively - together predicted $94 \%$ of the observed variability in UTHg measured in samples collected at the Browns Island wetland over two tidal cycles at two sites for each of three seasonal deployments. The strength of this relationship permitted us to use high-resolution in situ measurements of turbidity and FDOM to quantitatively estimate the tidally driven exchange of UTHg between the Browns Island wetland and the surrounding estuary. Longer-term monitoring provided results significantly different results than those obtained from one or a few tidal cycles. Monitoring both the dissolved and particulate phases was important because the relative contribution of each phase to the flux was tidally dependent. Longer-term studies such as this one and more effective proxies are needed to better understand $\mathrm{Hg}$ dynamics in tidal systems.

Acknowledgement We would like to thank the field and lab staff of the United States Geological Survey California Water Science Center and the California Department of Fish and Game Moss Landing Laboratory. In particular, we would like to express appreciation for the contributions of Megan Lionberger, Gail Wheeler, Erica Kalve, Will Kerlin, Matt Kerlin, Travis Von Dessonneck, Brad Sullivan, Paul Buchanan, Connie Clapton, Autumn Bohnema, and Greg Brewster. We enjoyed many useful discussions with David Krabbenhoft, George Aiken, and Gary Gill, and we thank them for their input. We would also like to thank Matt Cohen, Ann Chalmers, Tonya Clayton, and the 
anonymous reviewers who helped improve the manuscript. This work was supported by funding from the California Bay Delta Authority Ecosystem Restoration and Drinking Water Programs (grant ERP-00G01) and matching funds from the United States Geological Survey Cooperative Research Program.

Open Access This article is distributed under the terms of the Creative Commons Attribution License which permits any use, distribution, and reproduction in any medium, provided the original author(s) and the source are credited.

\section{References}

Abu-Saba, K. E., and L. W. Tang. 2000. Watershed management of mercury in the San Francisco bay estuary: total maximum daily load. California Regional Water Quality Control Board, 170. California Regional Water Quality Control Board, San Francisco Bay Region.

Adams, E.M., and P.C. Frederick. 2008. Effects of methylmercury and spatial complexity on foraging behavior and foraging efficiency in juvenile white ibises (Eudocimus albus). Environmental Toxicology and Chemistry 27: 1708-1712.

Alpers, C. N., M. P. Hunerlach, J. T. May, and R. L. Hothem. 2005. Mercury contamination from historical gold mining in California. U.S. Geological Survey. Fact Sheet 2005-3014 v.1.1: 6 p.

Amirbahman, A., A.L. Reid, T.A. Haines, J.S. Kahl, and C. Arnold. 2002. Association of methylmercury with dissolved humic acids. Environmental Science \& Technology 36: 690-695.

Bergamaschi, B.A., J.A. Fleck, B.D. Downing, E. Boss, B. Pellerin, N.K. Ganju, D. Schoellhamer, W. Heim, M. Stephenson, and R. Fujii. 2011. Methyl mercury dynamics in a tidal wetland quantified using in situ optical measurements. Limnology and Oceanography 56: 1355-1371.

Bergamaschi, B.A., D.P. Krabbenhoft, G.R. Aiken, E. Patino, D.G. Rumbold, and W.H. Orem. 2012. Tidally driven export of dissolved organic carbon, total mercury, and methylmercury from a mangrove-dominated estuary. Environmental Science \& Technology 46: $1371-1378$

Bird, S. M., M. S. Fram, and K. L. Crepeau. 2003. Method of analysis by the U.S. Geological Survey California District Sacramento Laboratory-Determination of dissolved organic carbon in water by high temperature catalytic oxidation, method validation, and quality-control practices. In U. S. Geological Survey, Open-File Report 03-366, ed. U.S. Geological Survey. http://pubs.usgs.gov/ of/2003/ofr03366

California Department of Water Resources. 2010. California Data Exchange Center (CDEC). http://cdec.water.ca.gov: CDEC. Accessed June 1, 2011.

Conaway, C.H., S. Squire, R.P. Mason, and A.R. Flegal. 2003. Mercury speciation in the San Francisco Bay estuary. Marine Chemistry 80: 199-225.

Crump, K.L., and V.L. Trudeau. 2009. Mercury-induced reproductive impairment in fish. Environmental Toxicology and Chemistry 28: 895-907.

Domagalski, J. 1998. Occurrence and transport of total mercury and methyl mercury in the Sacramento River Basin, California. Journal of Geochemical Exploration 64: 277-291.

Domagalski, J. 2001. Mercury and methylmercury in water and sediment of the Sacramento River Basin, California. Applied Geochemistry 16: 1677-1691.

Downing, B.D., B.A. Bergamaschi, D.G. Evans, and E. Boss. 2008. Assessing contribution of DOC from sediments to a drinkingwater reservoir using optical profiling. Lake and Reservoir Management 24: 381-391.
Downing, B.D., E. Boss, B.A. Bergamaschi, J.A. Fleck, M.A. Lionberger, N.K. Ganju, D.H. Schoellhamer, and R. Fujii. 2009. Quantifying fluxes and characterizing compositional changes of dissolved organic matter in aquatic systems in situ using combined acoustic and optical measurements. Limnology and Oceanography: Methods 7: 119-131.

Drexler, J.Z., R.L. Snyder, D. Spano, and U.K.T. Paw. 2004. A review of models and micrometeorological methods used to estimate wetland evapotranspiration. Hydrological Processes 18: 20712101.

Eagles-Smith, C.A., and J.T. Ackerman. 2009. Rapid changes in small fish mercury concentrations in estuarine wetlands: implications for wildlife risk and monitoring programs. Environmental Science \& Technology 43: 8658-8664.

Eckard, R.S., P.J. Hernes, B.A. Bergamaschi, R. Stepanauskas, and C. Kendall. 2007. Landscape scale controls on the vascular plant component of dissolved organic carbon across a freshwater delta. Geochimica Et Cosmochimica Acta 71: 5968-5984.

Edwards, T. K., and G. D. Glysson. 1999. Field methods for measurement of fluvial sediment. In U.S. Geological Survey, Techniques of Water-Resources Investigations, Book 3, Chapter C2, ed. U.S. Geological Survey.

Esbensen, K., D. Guyot, F. Westad, and L. P. Houmoller. 2002. Multivariate data analysis in practice: An introduction to multivariate data analysis, 5 ed. Camo, inc.

Ganju, N.K., D.H. Schoellhamer, and B.A. Bergamaschi. 2005. Suspended sediment fluxes in a tidal wetland: measurement, controlling factors, and error analysis. Estuaries 28: 812822.

Gartner, J.W. 2004. Estimating suspended solids concentrations from backscatter intensity measured by acoustic Doppler current profiler in San Francisco Bay, California. Marine Geology 211: 169187.

Gray, J. R., G. D. Glysson, L. M. Turcios, and G. E. Schwarz. 2000. Comparability of Suspended-Sediment Concentration and Total Suspended Solids Data, In U.S. Geological Survey WaterResources Investigations Report 00-4191, ed. U.S. Geological Survey. http://pubs.usgs.gov/wri/wri004191

Hall, B.D., G.R. Aiken, D.P. Krabbenhoft, M. Marvin-Dipasquale, and C.M. Swarzenski. 2008. Wetlands as principal zones of methylmercury production in southern Louisiana and the Gulf of Mexico region. Environmental Pollution 154: 124-134.

Jassby, A.D., and J.E. Cloern. 2000. Organic matter sources and rehabilitation of the Sacramento-San Joaquin Delta (California, USA). Aquatic Conservation: Marine and Freshwater Ecosystems 10: 323-352.

Kraus, T.E.C., B.A. Bergamaschi, P.J. Hernes, R.G.M. Spencer, R. Stepanauskas, C. Kendall, R.F. Losee, and R. Fujii. 2008. Assessing the contribution of wetlands and subsided islands to dissolved organic matter and disinfection byproduct precursors in the Sacramento-San Joaquin River Delta: a geochemical approach. Organic Geochemistry 39: 1302-1318.

Mason, R.P., E.H. Kim, J. Cornwell, and D. Heyes. 2006. An examination of the factors influencing the flux of mercury, methylmercury and other constituents from estuarine sediment. Marine Chemistry 102: 96-110.

Merritt, K.A., and A. Amirbahman. 2009. Mercury methylation dynamics in estuarine and coastal marine environments - a critical review. Earth-Science Reviews 96: 54-66.

Mitchell, C.P.J., and C.C. Gilmour. 2008. Methylmercury production in a Chesapeake Bay salt marsh. Journal of Geophysical Research: Biogeosciences 113: G00C04. doi:10.1029/ 2008JG000765.

Mitro, M.G., D.C. Evers, M.W. Meyer, and W.H. Piper. 2008. Common loon survival rates and mercury in New England and Wisconsin. Journal of Wildlife Management 72: 665-673. 
Murray, A.L., and T. Spencer. 1997. On the wisdom of calculating annual material budgets in tidal wetlands. Marine Ecology Progress Series 150: 207-216.

Pellerin, B.A., B.D. Downing, C. Kendall, R.A. Dahlgren, T.E.C. Kraus, J. Saraceno, R.G.M. Spencer, and B.A. Bergamaschi. 2009. Assessing the sources and magnitude of diurnal nitrate variability in the San Joaquin River (California) with an in situ optical nitrate sensor and dual nitrate isotopes. Freshwater Biology 54: 376-387.

Puckett, H. M., and B. H. V. Buuren. 2000. Quality assurance project plan for the CALFED Project: "An assessment of ecological and human health impacts of mercury in the Bay-Delta watershed". California Department of Fish and Game.

Ravichandran, M. 2004. Interactions between mercury and dissolved organic matter-a review. Chemosphere 55: 319-331.

Saraceno, J.F., B.A. Pellerin, B.D. Downing, E. Boss, Bachand PaM, and B.A. Bergamaschi. 2009. High-frequency in situ optical measurements during a storm event: assessing relationships between dissolved organic matter, sediment concentrations, and hydrologic processes. Journal of Geophysical Research: Biogeosciences 114: G00F09. doi:10.1029/2009jg000989.

Selvendiran, P., C.T. Driscoll, J.T. Bushey, and M.R. Montesdeoca. 2008. Wetland influence on mercury fate and transport in a temperate forested watershed. Environmental Pollution 154: $46-55$.
Shanley, J.B., M.A. Mast, D.H. Campbell, G.R. Aiken, D.P. Krabbenhoft, R.J. Hunt, J.F. Walker, P.F. Schuster, A. Chalmers, B.T. Aulenbach, N.E. Peters, M. Marvin-DiPasquale, D.W. Clow, and M.M. Shafer. 2008. Comparison of total mercury and methylmercury cycling at five sites using the small watershed approach. Environmental Pollution 154: 143-154.

Smith, J.T., L.A. Walker, R.F. Shore, S. Durell, P.D. Howe, and M. Taylor. 2009. Do estuaries pose a toxic contamination risk for wading birds? Ecotoxicology 18: 906-917.

Spencer, R.G.M., B.A. Pellerin, B.A. Bergamaschi, B.D. Downing, T.E.C. Kraus, D.R. Smart, R.A. Dalhgren, and P.J. Hernes. 2007. Diurnal variability in riverine dissolved organic matter composition determined by in situ optical measurement in the San Joaquin River (California, USA). Hydrological Processes 21: 3181-3189.

U.S. Environmental Protection Agency. 1996. Method 1669: Sampling ambient water for trace metals at EPA water quality criteria levels. U.S. Environmental Protection Agency, Office of Water.

U.S. Environmental Protection Agency. 2002. Method 1631, Revision E: Mercury in water by oxidation, purge and trap, and cold vapor atomic fluorescence spectrometry. U.S. Environmental Protection Agency, Office of Water.

Wagner, R. J., R. W. Boulger, Jr., C. J. Oblinger, and B. A. Smith. 2006. Guidelines and standard procedures for continuous waterquality monitors - station operation, record computation, and data reporting. U.S. Geological Survey Techniques and Methods : 51 p. 